SVU- International Journal of Veterinary Sciences, 4 (4): 22-32, 2021.

Print ISSN: 2535-1826

Online ISSN: 2535-1877

\title{
Histological features of the spleen and pancreas of the Egyptian Nile Monitor Lizard
}

\section{(Varanus niloticus)}

\author{
Elsayed S. I. Mohammed ${ }^{1}$, Fatma A. Madkour ${ }^{2}$ and Rasha Radey ${ }^{3}$
}

${ }^{1}$ Department of Histology and Cytology, Faculty of Veterinary Medicine, South Valley University,83523, Qena, Egypt, ${ }^{2}$ Department of Anatomy and Embryology, Faculty of Veterinary Medicine, South Valley University,83523, Qena, Egypt, ${ }^{3}$ Animal Health Research Institute, Qena Laboratory, Qena, Egypt.

\section{Abstract}

The present study investigated the histological features of the spleen and pancreas of the Egyptian Nile monitor lizard (Varanus niloticus). After gross observations the representative samples were collected from three adult male monitor lizards and were processed for histological examination. Grossly, the spleen was brownish in color and embedded in the mesentery near the stomach and pancreas. The pancreas was yellowish in color and consisted of a ventrally placed principal lobe which was pyramidal and extended in the mesentery, whereas the dorsally located splenic lobe was small and was attached to the spleen. a single duct was emerged from the pancreas. Histologically, the spleen was nodular and was encapsulated by the connective tissue capsule covered by mesothelium. it was composed of white and red pulps. Many ellipsoids, melano-macrophage centers, periarterial and periellipsoidal lymphatic sheaths (PALS and PELS; respectively) were observed. The pancreas demonstrated a thicker capsule covered by mesothelium and the exocrine portion was formed of tubule-acinar cells. Main pancreatic duct passed across the length of the pancreas and was lined by stratified cuboidal epithelium. The islets were found in the ventral lobe where it was in various sizes. This is the first report about the histological structure of the spleen and pancreas of the Egyptian Nile monitor lizard, where the spleen showed a unique structure while the pancreas was similar to what was described in other varanus species. The information in this study will be a baseline knowledge for future studies regarding endocrine or immune organs in this species.

Keywords: Melano-macrophages, Pancreas, Reptile, Spleen, Varanus.

DOI: 10.21608/svu.2021.96063.1149 Received: September 15, 2021 Accepted: October 20, 2021 Published: October 24, 2021*Corresponding Authors: Elsayed S. I. Mohammed E-mail: esi.mohammed@vet.svu.edu.eg Citation: Mohammed et al., Histological features of the spleen and pancreas of the Egyptian Nile Monitor Lizard (Varanus niloticus). SVU-IJVS 2021, 4 (4): 22-32.

Copyright: (C) Mohammed et al. This is an open access article distributed under the terms of the creative common attribution license, which permits unrestricted use, distribution and reproduction in any medium provided the original author and source are created.

Competing interest: The authors have declared that no competing interest exists. 


\section{Introduction}

During evolution, reptiles have been exposed to hundreds of millions of years of radiation which have affected their morphological, behavioral, ecological, lifehistory and defensive strategies to adapt to the certain demands and harsh environment that they faced (Pianka and Vitt, 2003; Fry et al., 2006). The class Reptilia comprises of around 7500 species, including well known species as: alligators, turtles, lizards and snakes (Jacobson, 2007).

Reptiles have been suggested as a useful future experimental animal model for studies focusing on the physiological regulation of the digestive process which may be more useful than other commonly used experimental animals such as rats, rabbits and pigs as reptiles have good responses to feeding (Secor and Diamond 1998)

The Egyptian Nile monitor lizard (Varanus niloticus) (Linnaeus, 1766); is considered one of the most voracious and largest predators in Africa. It can be found along the river Nile and its surrounding water canals, swamps, pools and lakes (Capula, 1990; Bennett, 1995; Smith et al., 2008; Ahmed et al., 2009; 2018; Awad and Mohamadain, 2020). The first report about the hematological and biochemical parameters of free-ranging female Nile monitor lizards in Egypt was reported by Moustafa et al. (2013).

The morphological and histological structure of the skin, digestive tract, liver, renal tissue, ductus deferens and pancreas of some reptiles have been previously reported ( Ahmed et al, 2009; 2018; Hamny et al., 2016; Srichairat et al., 2018; Awad and Mohamadain, 2020; Awad et al., 2021; Shaker and Ibrahim, 2021).

The histological features of the reptilian spleen have been investigated before (Borysenko and Cooper, 1972; Wetherall and Turner, 1972; Borysenko, 1976;
Hussein et al., 1978a,b, 1979a,b; Chen and Nie, 1993, 1995; Bao et al., 2009). The reptilian spleen was also reported to be similar to that of other vertebrates and plays key roles in hemopoiesis, antigen trapping, and initiation of the cellular immune responses (Kroese, 1983; Kroese et al., 1985). Furthermore, due to the absence of other peripheral lymph organs, such as the Peyer's patches and lymph nodes in mammals, or the Bursa of Fabricius in birds, the reptilian spleen has a great importance as a functional lymphoid organ in when compared to mammalian spleen (Rooney et al., 2003).

The pancreas of lizards is more complex than snakes and have two or three lobes. One lobe runs along the bile duct towards the gall bladder, the other lobe runs to the small intestine, and typically a thin lobe runs to the spleen (Miller and Lagios, 1970). Previous reports stated that there are little differences in the histological structure of the exocrine portion of the pancreas in reptiles in comparison to mammals. Miller and Lagios (1970) reported that the exocrine portion of the reptile pancreas consisted of branching tubules not acini as in mammals. The bipolar cells or zymogen cells function similarly to mammals in the processes of protein secretion; granule formation, and granule discharge. Other reports revealed that there is a great variation in the pancreatic islets' morphology between different reptile orders (Miller, 1962; Moscona, 1990). Available literature revealed that there is no information on the morphological and histological structure of the spleen and pancreas of the Egyptian Nile monitor lizard (Varanus niloticus). Therefore, the aim of this study was to investigate the histological features of the spleen and pancreas of the Egyptian Nile monitor lizard (Varanus niloticus).

\section{Material and Methods}




\section{Animals and Samples collection}

Three adult male monitor lizards were captured by the fishermen from local water canals originating from the River Nile around the city of Qena, Egypt during the summer of 2017 (June to August 2017). After euthanization of animals as previously described by Moustafa et al. (2013) and Ahmed et al. (2018), (Fig. 1A and $\mathrm{B}$ ), the spleen and pancreas were removed, washed with normal saline solution and then fixed in $4 \%$ neutral buffered formalin (NBF) (Fig. 1C-F). The animals have been used for experimental
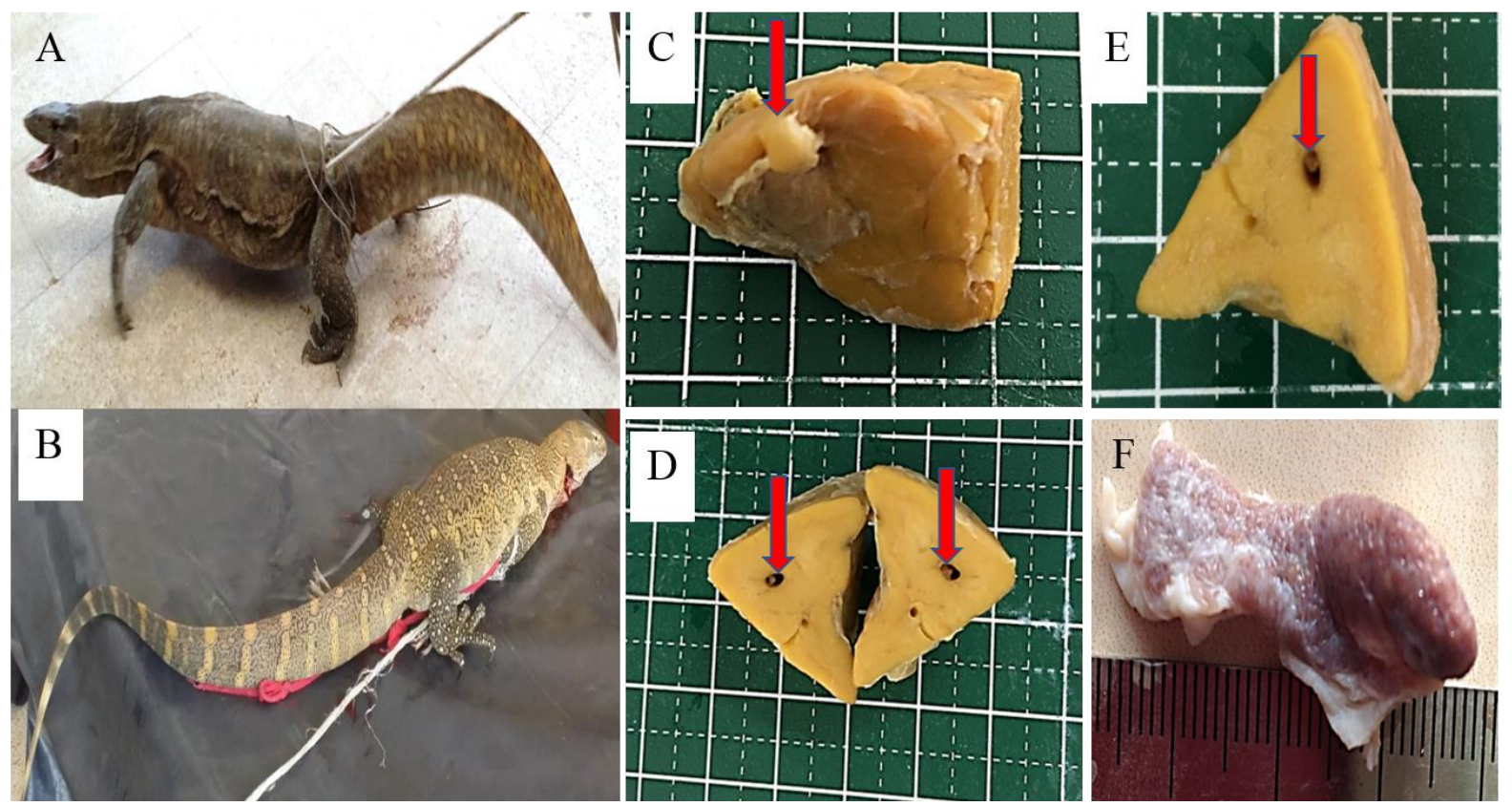

Figure 1: Morphological features of the Nile monitor lizard and its spleen and pancreas.

A and B show Nile monitor lizards; A alive and B scarified lizards. C, D and E show a partially dissected pancreas of the Nile monitor lizard fixed in NBF; red arrows indicate the main pancreatic duct. F shows the spleen of the Nile monitor lizard.

procedures after the agreement of the Animal research and ethics Committee and endorsed by the University of South Valley Animal Welfare and Ethics Committee.

\section{Histological observations}

For histological observations, spleen and pancreas samples were washed in normal saline solution and then the representative samples were fixed in $4 \% \mathrm{NBF}$ for $48 \mathrm{hrs}$, dehydrated in ascending grades of alcohol, cleared in methyl benzoate and embedded

\section{Semithin sectioning}

Small pieces from the splenic and pancreatic tissues of monitor lizards were collected for semithin sections. The specimens were fixed in $2.5 \%$ glutaraldehyde then post fixed in $1 \%$ osmic acid at $4^{\circ} \mathrm{C}$ for $2 \mathrm{hr}$. Then the specimens were dehydrated in ascending grades of alcohol then embedded in Epon 812 resin (Electron Microscopy Sciences; USA). 
Resin-embedded samples were left to polymerize at $60^{\circ} \mathrm{C}$ for 2-3 days. Semithin sections $(0.5 \mu \mathrm{m})$ were cut using an of intestines as a triangular prismatic organ which appeared pyramidal in cross section (Fig. 1C-E). Both lobes of the pancreas
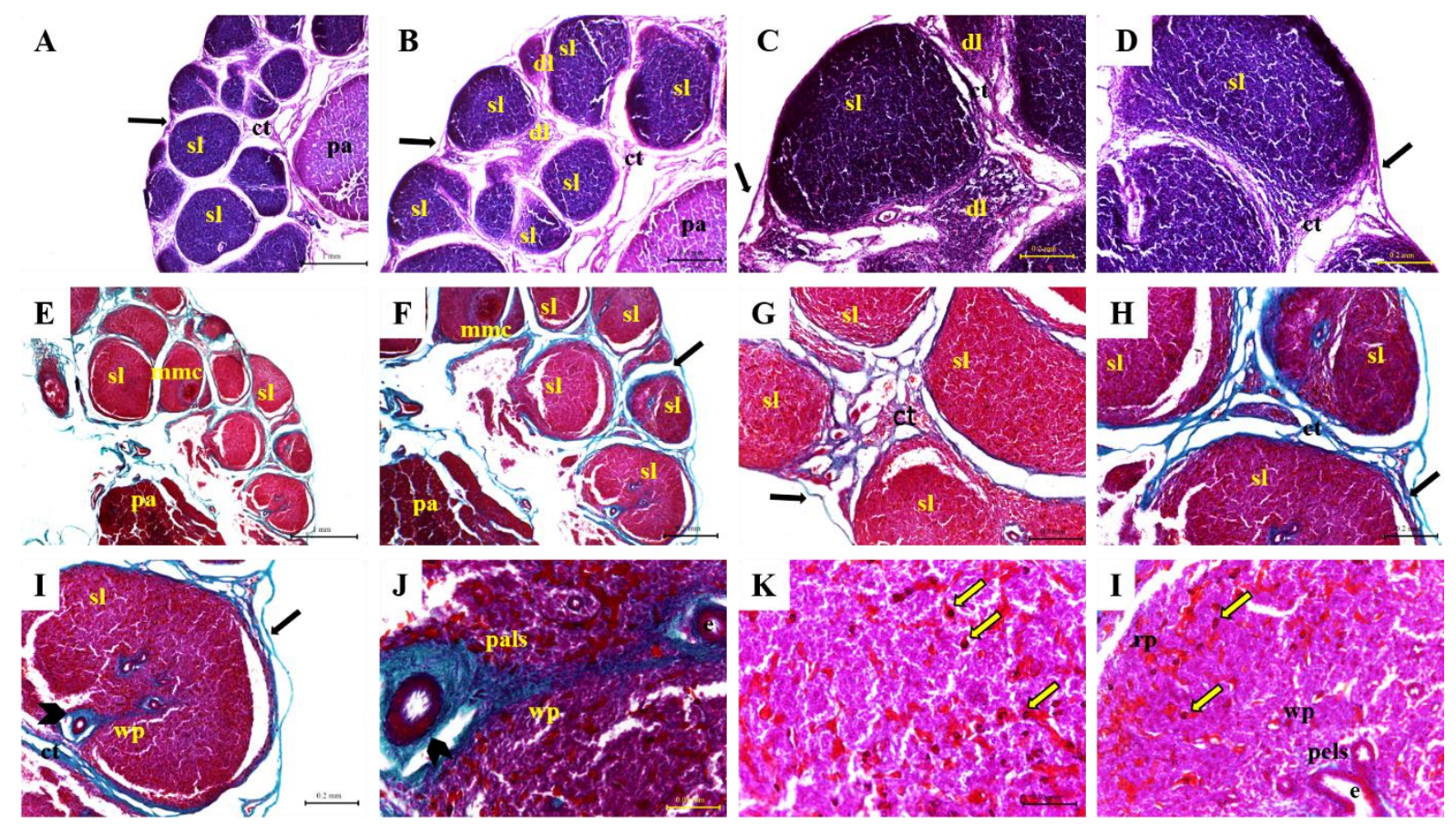

Figure 2: Photomicrographs of the spleen of the Nile Monitor Lizard (Varanus niloticus) showing: (Black arrows) Capsule, (Pa) Splenic lobe of the pancreas, (Sl) Splenic follicle, (ct) Connective tissue separating the follicles and contains blood vessels and diffuse lymphocytic infiltration, (mmc) Melanomacrophages center, (wp) white pulp of the spleen, (rp) Red pulp of the spleen, (Black arrow heads) Follicular arteriole, (pals) Periarterial lymphatic sheath, (pels) Periellipsoidal Lymphatic sheath, (Yellow arrows) Melano-macrophages, (e) Ellipsoid, (dl) Diffuse lymphocytic infiltration. A-D stained with $\mathrm{H}$ and $\mathrm{E}$ stain while F-L stained with Crossman's trichrome stain.

ultramicrotome Ultracut E (Reichert-Leica) and stained with toluidine blue (Burns, 1978).

\section{Results}

The results of the anatomical observations showed that the spleen of the Nile monitor lizard was brownish in color with two ends; rounded and flat ends. It appeared granular and was embedded in the mesentery near to the pancreas and stomach (Fig. 1 D). Grossly, the pancreas of Nile monitor lizard consisted of two lobes, namely; the dorsal lobe (splenic lobe) and the ventral lobe (duodenal lobe). The dorsal lobe was oval and adhered with the spleen, while the ventral lobe was located in the cranial part were white-yellow to yellowish in color. The pancreas was spread out in the mesentery between the cranial part of intestine and the pyloric stomach. A single pancreatic duct emerged from the caudal edge of the pancreas and opened into the cranial part of small intestine near the openings of the common bile ducts from the liver and gallbladder.

Histologically, the spleen was covered externally be visceral peritoneum formed of mesothelial and sub-mesothelial layer attached to a thin layer of collagenous connective tissue that surrounded numerous lymphatic nodules (Fig. 2A-H). A part of the splenic lobe of the pancreas was observed as it adhered to the spleen (Fig. E and F). Each splenic nodule was encapsulated and formed of follicular 
arteriole and several ellipsoids surrounded by lymphatic cells forming the white pulp of the spleen whereas the red pulp (Fig. 2 I and $\mathrm{J}$ ) was formed of the other portion of the follicle and included lymphatic cells, dendritic cells, macrophages, red blood cells and the melano-macrophages (Fig. 2K and I) which were found in both red and white pulp. surrounded by reticular cells and collagen fibers in which enclosed erythrocytes were found occasionally. In some follicles melano-macrophage centers were also observed. The red pulp comprised the splenic cords and the splenic sinuses (Fig. 3 A-I and Fig. 4 A-F). There was no clear demarcation between red and white pulps of the spleen of the Nile monitor lizard.

The histological observations of the
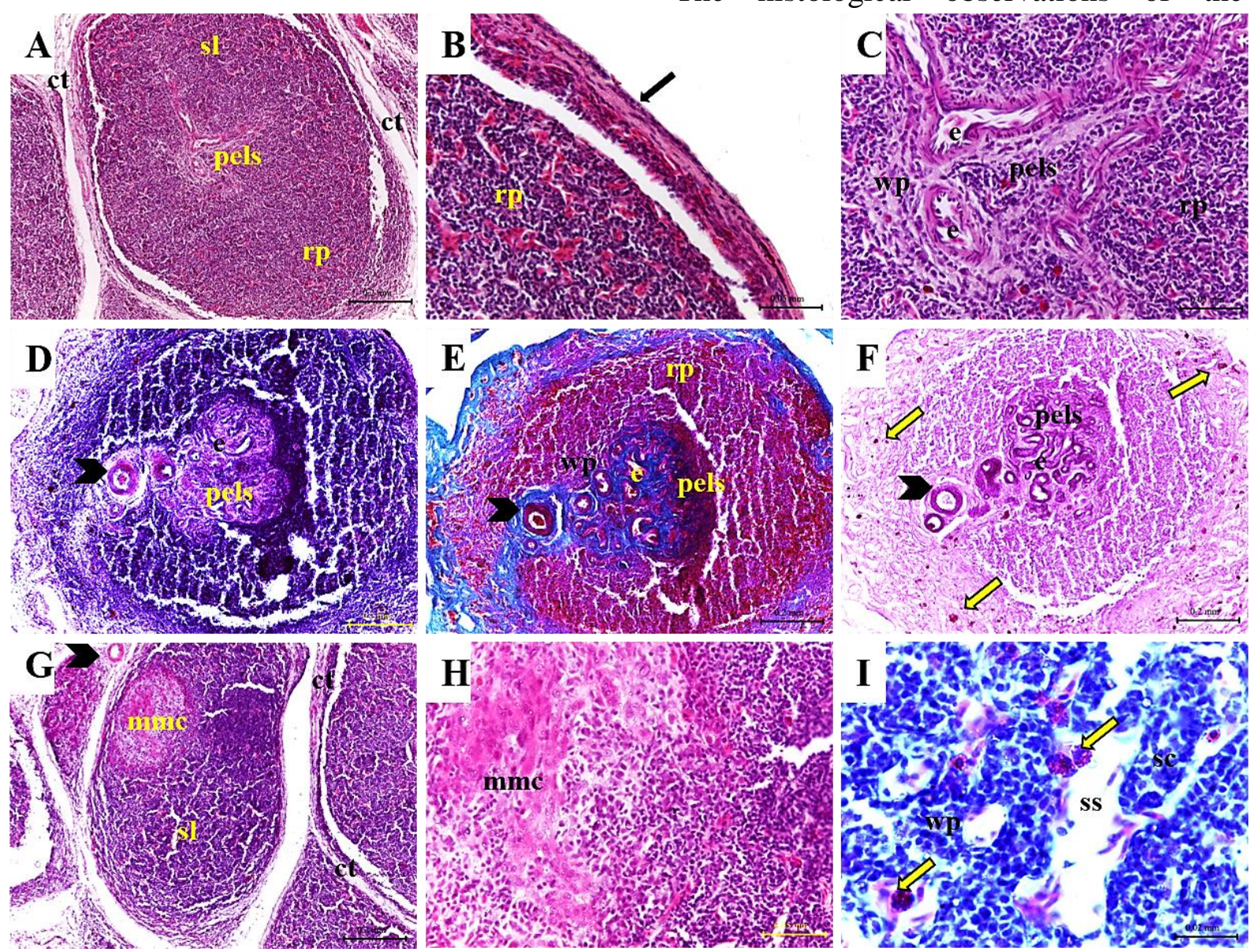

Figure 3: Photomicrographs of the spleen of the Nile Monitor Lizard (Varanus niloticus) showing: (Black arrows) Capsule, (Sl) Splenic follicle, (ct) Connective tissue separating the follicles and contains blood vessels and diffuse lymphocytic infiltration, (mmc) Melano-macrophages center, (wp) white pulp of the spleen, (rp) Red pulp of the spleen, (Black arrow heads) Follicular arteriole, (pals) Periarterial lymphatic sheath, (pels) Periellipsoidal Lymphatic sheath, (Yellow arrows) Melano-macrophages, (e) Ellipsoid, (ss) Splenic sinusoid, (sc) Splenic cord, (Green arrow) Lymphocyte, (Red arrow) Branched dendritic cells, (Grey arrow) Red blood cell. A-D and G-I stained with H and E stain while E stained with Crossman's trichrome stain and $\mathrm{F}$ stained with AB-PAS techniques.

The lymphoid tissue of the spleen was arranged around the arterioles as ellipsoids forming periarteriolar (PALS) and periellipsoidal lymphatic sheaths (PELS) (Fig. 2, 3 and 4), respectively. Ellipsoids consisted of an endothelial cell layer pancreas of the Nile monitor lizard revealed that the pancreas was encapsulated by a thin connective tissue capsule covered by mesothelium. The exocrine pancreas formed of the tubuloacinar cells, ducts, and blood vessels in 
both pancreatic lobes. Typical pancreatic acini with pyramidal cells, zymogen granules forming apical acidophilia at the apical portion of the cells and basal basophilia can be observed representing the ergastoplasm.
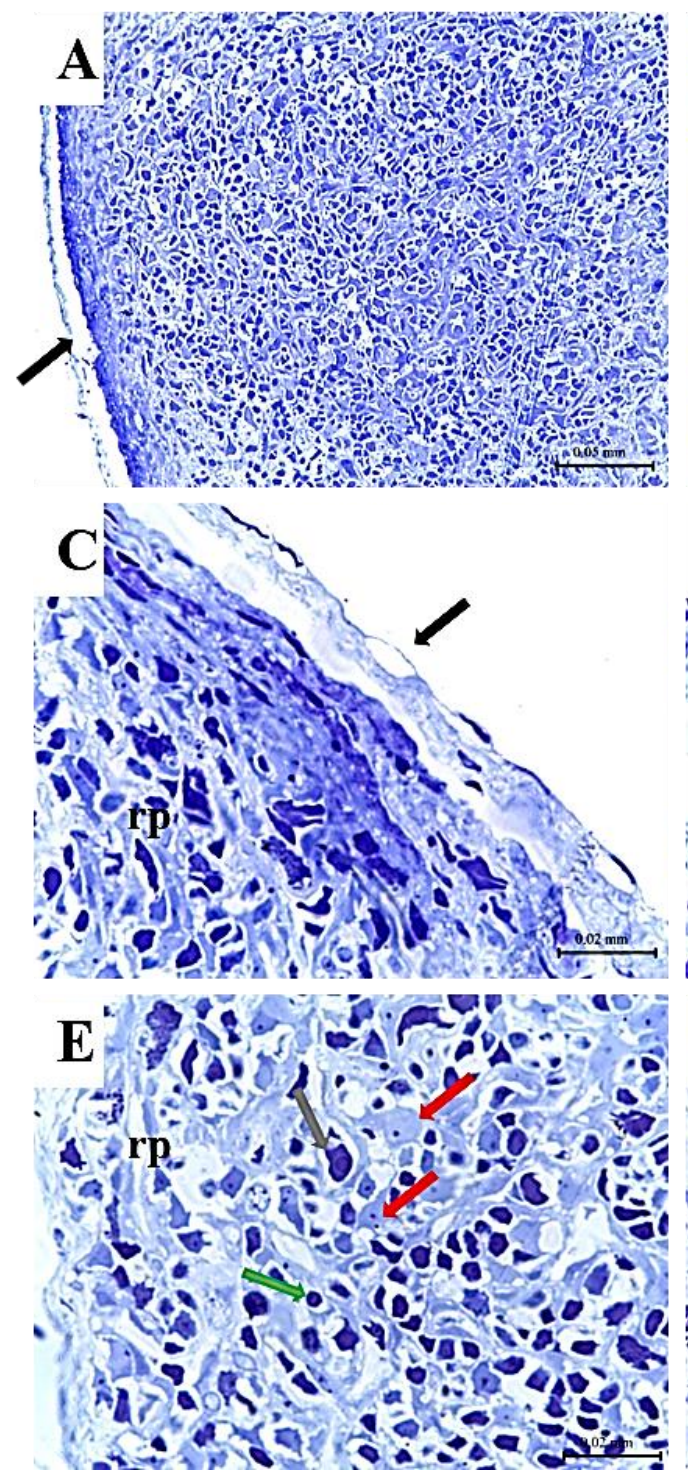

Figure 4: Photomicrographs of the semithin sections of the spleen of the Nile Monitor Lizard (Varanus niloticus) showing: (Black arrows) Capsule, (ct) Connective tissue separating the follicles and contains blood vessels and diffuse lymphocytic infiltration, (wp) white pulp of the spleen, (rp) Red pulp of the spleen, (pels) Periellipsoidal Lymphatic sheath, (Yellow arrows) Melano-macrophages, (e) Ellipsoid, (rbcs) Red blood cells. A-F stained with toluidine blue stain.

Several intercalated ducts and interlobular ducts that were lined by low to high cuboidal epithelium and were observed scattered among the exocrine pancreatic tissue (Fig. 5). The main pancreatic duct was found in the center of the triangular shape of the pancreas and run across the length of the pancreas from head to tail. The main pancreatic duct of the Nile monitor lizard was lined by stratified cuboidal epithelium. The endocrine portion or Langerhans islet which could only be detected at the ventral lobe of
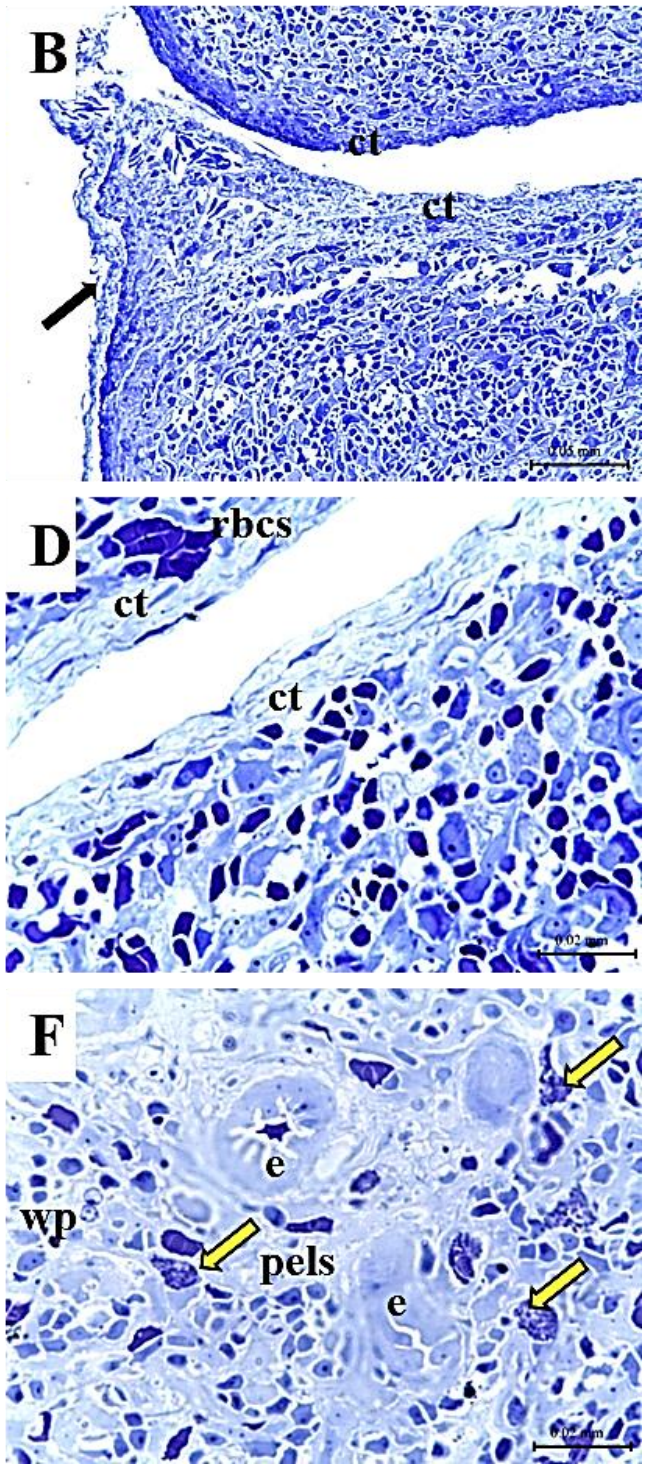

pancreas. The shape and size of the islets of Langerhans was of various forms. It was spread in small cords, large cord or rounded areas enclosing blood vessels among the exocrine of the pancreas (Fig. 6). 


\section{Discussion}

In the current study we report the histological description of the spleen and pancreas of the Nile monitor lizard (Varanus niloticus) for the very first time.
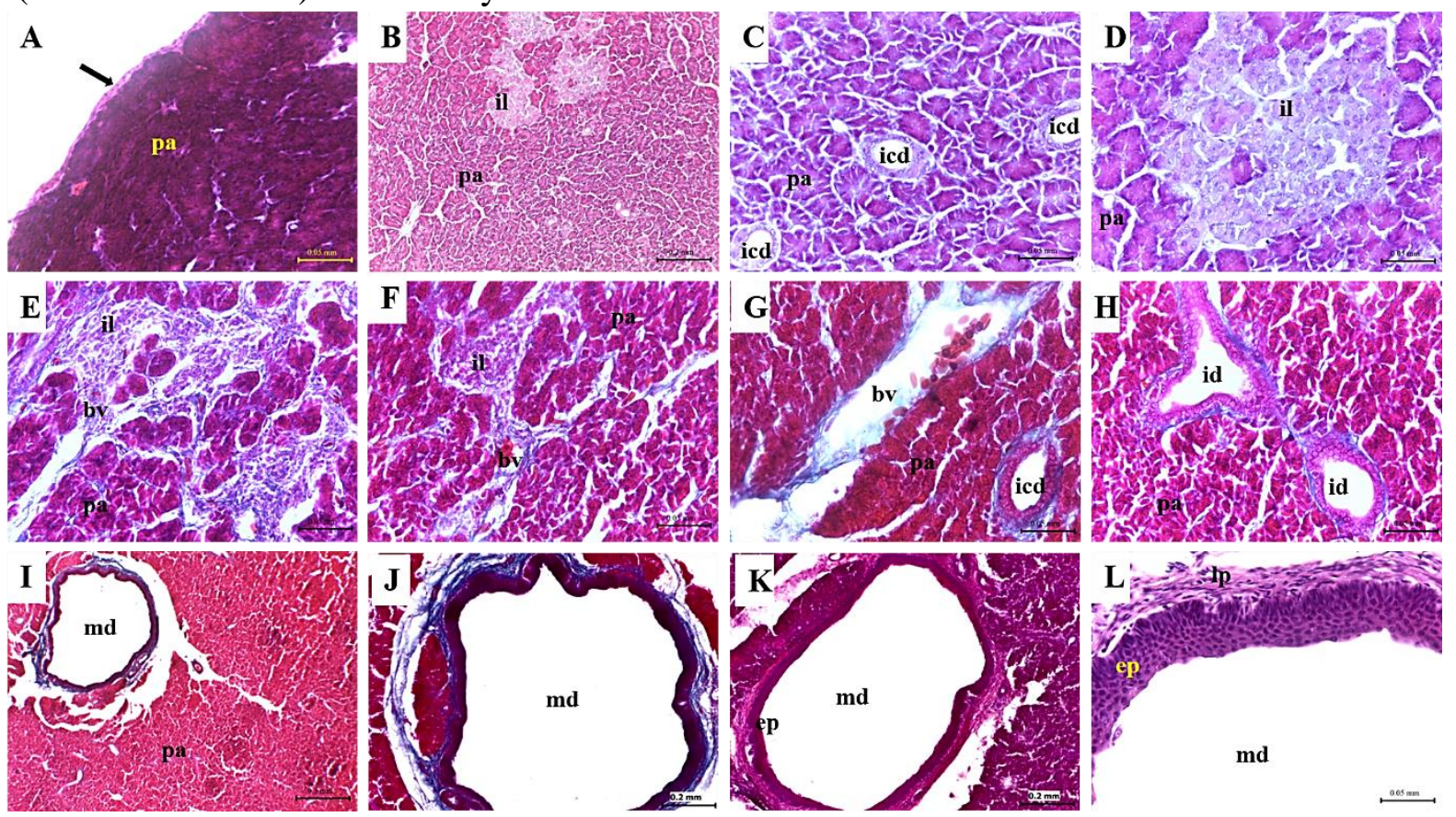

Figure 5: Photomicrographs of the spleen of the Nile Monitor Lizard (Varanus niloticus) showing: (Black arrows) Capsule, (pa) Pancreatic acini, (il) Islets of Langerhans, (icd) intercalated duct, (id) interlobular duct, (md) Main pancreatic duct, (ep) stratified cuboidal epithelium, (lp) Lamina propria, (bv) blood vessel. A-D, K and L stained with $\mathrm{H}$ and E stain while E-J stained with Crossman's trichrome stain.

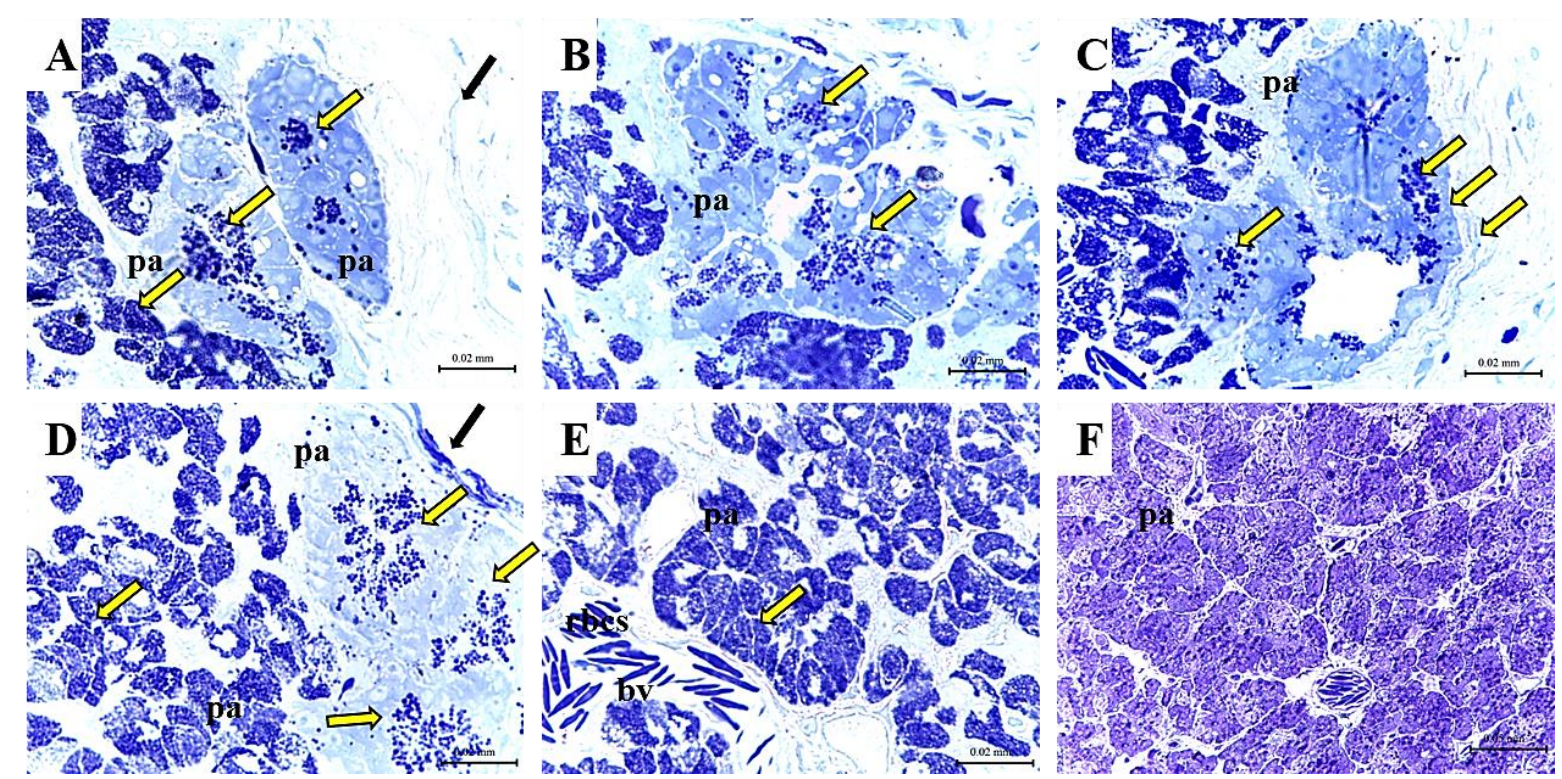

Figure 6: Photomicrographs of the semithin sections of the pancreas of the Nile Monitor Lizard (Varanus niloticus) at different directions showing: (Black arrows) Capsule, (pa) Pancreatic acini, (Yellow arrows) Zymogen granules, (bv) blood vessel, (rbcs) Red blood cells. A-F stained with toluidine blue stain. 
numerous melano-macrophages, melanomacrophage centers, PALS and PELS were observed in the spleen; (3) the exocrine pancreas was tubule-acinar gland; (4) islets of Langerhans could not be detected in the splenic lobe of the pancreas and the main duct was lined by stratified cuboidal epithelium. The structure of the white pulp of the spleen of the Nile monitor lizard was similar to some extent to what was described by Leceta and Zapata (1991) in the turtles.

Melano-macrophages were frequently seen in both the red and white pulps of the spleen. Earlier reports on melanomacrophages were occasionally seen among the hepatocytes (Ahmed et al., 2018), or in the spleen and kidney of other species (Leknes, 2007) tallied with the observations of present study. Melano-macrophage cells might be a type of the defense system against totoxic substances and their higher number may be an indication of the rate of pollution (Fenoglio et al. 2005; Leknes, 2007). The number of these cells varied among non-mammalian vertebrates. They were numerous in amphibians (Moura et al. 2017; Gutierre et al., 2018) and form melano-macrophages centers in the splenic, renal and hepatic tissue of teleost (Agius and Roberts, 2003).

Previous studies reported that the histological structure of the exocrine pancreas in reptiles was similar to that of mammals (Hamny, 2016) with some differences where the exocrine parenchyma of the reptile pancreas consists of tubuleacinar glands rather than typical acini seen in mammals (Miller, 1970). In this study, typical acini can be found in the ventral lobe more than the splenic lobe and in the periphery of the pancreas more than the center area. The islets of Langerhans could not be detected in the splenic lobe similar to the report of Hamny (2016) in the water monitor. Previous report by Miller (1960) stated that most reptilian endocrine tissue lacked a clear demarcation from exocrine portion of the pancreas. Miller (1962) reported that the islets of Langerhans in turtle were smaller and diffusely distributed, while crocodilian islets were larger and highly branched. Our results showed that the pancreatic islets of the Nile monitor lizard could be found as diffuse, branched or rounded islets. The results of the current study and the previous studies on various species of reptiles revealed that there was a great difference in the morphology and histology of the pancreatic islet between different reptilian orders.

In conclusion, the spleen in Nile monitor lizard was formed of numerous encapsulated follicles that contained red and white pulps without a clear demarcation between them. The pancreas was consisted of two lobes which varied in their location. The ventral lobe was larger than the dorsal lobe. Both lobes had similar histological structure except the fact that islets of Langerhans could only be detected in the ventral lobe. This study will provide information for wildlife veterinarians and researchers to understand the structure and function of these endocrine and immune organs of this species.

\section{Conflicts of interest}

The authors declare that they have no conflict of interest.

\section{Financial support}

This work was supported financially by the Faculty of Veterinary Medicine, South Valley University, Qena 83523, Egypt.

\section{Orcid}

Elsayed S. I. Mohammed; orcid.org/00000002-7884-8234.

Fatma A. Madkour; orcid.org/0000-00025641-9260. 
Rasha Radey; orcid.org/0000-0001-51207026.

\section{References}

Agius, C. and Roberts, R.J., 2003. Melanomacrophage centres and their role in fish pathology. Journal of fish diseases, 26(9):499-509.

Ahmed, Y.A., Abdelsabour-Khalaf, M. and Mohammed, E. S. I., 2018. Histological insight into the hepatic tissue of the Nile monitor (Varanus niloticus). J. Exp. Appl. Anim. Sci. 2 (3): 240-250.

Ahmed, Y.A., El-Hafez, A.A.E. and Zayed, A.E., 2009. Histological and histochemical studies on the esophagus, stomach and small intestines of Varanus niloticus. Journal of veterinary anatomy, 2(1):35-48.

Awad, M. and Mohamadain, D., 2020. Histochemical and ultrastructural investigations on the renal parenchyma of the Egyptian Nile Monitor Lizard (Varanus niloticus). Acta

Zoologica, 101(4):404-411.

Awad, M., Alshehri, M. and Hassaneen, A.S.A., 2021. Histological, Histochemical, and Ultrastructural Approach to the Ductus Deferens in Male Nile Monitor Lizard (Varanus niloticus). Microscopy and Microanalysis, 1-6.

Bancroft, J. D. and Layton, C., 2013. Bancroft's theory and practice of histological techniques, $7^{\text {th }}$ ed. New York, NY: Churchill Livingstone.

Bao, H.J., Li, M.Y., Wang, J., Qin, J.H., $\mathrm{Xu}$, C.S., Hei, N.N., Yang, P., Gandahi, J.A. and Chen, Q.S., 2009. Architecture of the blood-spleen barrier in the soft-shelled turtle, Pelodiseus sinensis. The Anatomical Record: Advances in Integrative Anatomy and Evolutionary Biology: Advances in Integrative Anatomy and
Evolutionary Biology, 292(8):10791087.

Bennett, D., 1995. A little book of monitor lizards: A guide to the monitor lizards of the world and their care in captivity. Aberdeen, Great Britain: Viper Press.

Borysenko, M. and Cooper, E.L. 1972. Lymphoid tissue in the snapping turtle, Chelydra serpentina. Journal of morphology, 138(4):487-497.

Borysenko, M., 1976. Changes in spleen histology in response to antigenic stimulation in the snapping turtle, Chelydra serpentine. Journal of morphology, 149(2), pp.223-241.

Burns, W. A.,1978. Thick sections: Technique and applications. B. F. Trump, \& R. J. Jones (eds). Diagnostic electron microscopy. New York, NY: John Wiley \& Sons.

Capula, M., 1990. The Macdonald Encyclopedia of Amphibians and Reptiles. London and Macdonald Coltd.

Chen, Q. and Nie Q., 1993. Structure and histochemical characters of spleen white pulp in Trionyx sinensis. Journal of Gansu Agricultural University 3:220-223.

Chen, Q. and Nie, Q., 1995. Studies on the microscopic and submicroscopic structure in the spleen of the turtle, Trionyx sinensis. Journal-Nanjing Agricultural University, 18:91-97.

Fenoglio, C., Boncompagni, E., Fasola, M., Gandini, C., Comizzoli, S., Milanesi, G. and Barni, S. 2005. Effects of environmental pollution on the liver parenchymal cells and Kupffermelanomacrophagic cells of the frog Rana esculenta. Ecotoxicology and environmental safety, 60(3):259-268.

Fry, B.G., Vidal, N., Norman, J.A., Vonk, F.J., Scheib, H., Ramjan, S.R., Kuruppu, S., Fung, K., Hedges, S.B., Richardson, M.K. and Hodgson, W.C., 2006. Early evolution of the venom system in lizards and 
snakes. Nature, 439(7076):584-588.

Gutierre, R.C., Jared, C., Antoniazzi, M.M., Coppi, A.A. and Egami, M.I., 2018. Melanomacrophage functions in the liver of the caecilian Siphonops annulatus. Journal of anatomy, 232(3):497-508.

Hamny, H., Iqbal, M., Wahyuni, S., Sabri, M., Jalaluddin, M. and Rinidar, R., 2016. STUDI ANATOMIS DAN HISTOLOGIS PANKREAS BIAWAK AIR (Varanus salvator) (Anatomical and Histological Study of the Pancreas of Water Monitor Lizard (Varanus salvator)). Jurnal Kedokteran Hewan-Indonesian Journal of Veterinary Sciences, 10(2):153-156.

Hussein, M.F., Badir, N., El Ridi, R. and Akef, M., 1978a. Differential effect of seasonal variation on lymphoid tissue of the lizard, Chalcides ocellatus. Developmental and Comparative Immunology, 2(2):297309.

Hussein, M.F., Badir, N., El Ridi, R. and Akef, M., 1978b. Effect of seasonal variation on lymphoid tissues of the lizards, Mabuya quinquetaeniata Licht. and Uromastyx aegyptia Forsk. Developmental and Comparative Immunology, 2(3):469-478.

Hussein, M.F., Badir, N., El Ridi, R. and Akef, M., 1979a. Lymphoid tissues of the snake, Spalerosophis diadema, in the different seasons. Developmental \& Comparative Immunology, 3:7788.

Hussein, M.F., Badir, N., El Ridi, R. and El Deeb, S., 1979b. Effect of seasonal variation on immune system of the lizard, Scincus scincus. Journal of Experimental Zoology, 209(1):91-96.

Jacobson, E.R., 2007. Overview of reptile biology, anatomy, and histology. In Infectious diseases and pathology of reptiles (15-144). CRC Press.

Kroese F.G.M., 1983. Antigen trapping in the spleen of the red eared turtle.
Developmental and Comparative

Immunology, 7:711-712.

Kroese F.G.M., Leceta J., Dopp E.A., Herraez M.P., Nieuwenhuis P. and Zapata A.G. 1985. Dendritic immune complex trapping cells in the spleen of the snake, Python reticulatus. Dev Comp Immunol 9:641-652.

Leceta, J. and Zapata, A.G. 1991. White pulp compartments in the spleen of the turtle Mauremys caspica. Cell and tissue research, 266(3), pp.605-613.

Leknes, I.L., 2007. Melano-macrophage centres and endocytic cells in kidney and spleen of pearl gouramy and platyfish (Anabantidae, Poeciliidae: Teleostei). Acta histochemica, 109(2):164-168.

Miller, M.R. and Lagios, M., 1970. The pancreas. In: Gans C, Parsons TC, editors. Biology of the reptilia. vol 3. New York: Academic Press; 319-346.

Miller, M.R., 1960. Pancreatic islet histology and carbohydrate metabolism in amphibians and reptiles. Diabetes, 9(4), pp.318-323.

Miller, M.R.,1962. Observations on the comparative histology of the reptilian pancreatic islet. General and Comparative Endocrinology, 2(4):407-414.

Moscona, A.A., 1990. Anatomy of the pancreas and Langerhans islets in snakes and lizards. The Anatomical Record, 227(2):232-244.

Moura, L.R., Santos, A.L.Q., Belleti, M.E., Vieira, L.G., Orpinelli, S.R.T. and De Simone, S.B.S., 2017. Morphological aspects of the liver of the freshwater turtle Phrynops geoffroanus Schweigger, 1812 (Testudines, Chelidae). Journal of Morphological Sciences, 26(3-4):0-0.

Moustafa, M.A.M., Ismail, M.N.E., Mohamed, A.E.S.A., Ali, A.O. and Tsubota, T., 2013. Hematologic and biochemical parameters of freeranging female Nile monitors in Egypt. Journal of wildlife diseases, 

49(3):750-754.

Pianka, E.R., Pianka, E.R. and Vitt, L.J., 2003. Lizards: windows to the evolution of diversity (Vol. 5). Berkeley, Los Angeles \& London: University of California Press.

Rooney, A.A., Bermudez, D.S. and Guillette Jr, L.J., 2003. Altered histology of the thymus and spleen in contaminant-exposed juvenile American alligators. Journal of Morphology, 256(3):349-359.

Secor, S.M. and Diamond, J., 1998. A vertebrate model of extreme physiological regulation. Nature, 395(6703):659-662.

Shaker, N.A. and Ibrahium, A.M., 2021. Anatomical and histological features of the gastrointestinal tract in the Nile crocodile, (crocodylus niloticus) with special reference to its arterial blood supply. Adv. Anim. Vet. Sci, 9(5):692-699.

Smith, K.T., Bhullar, B.A.S. and Holroyd, P.A., 2008. Earliest African record of the Varanus stem-clade (Squamata: Varanidae) from the Early Oligocene of Egypt. Journal of Vertebrate Paleontology, 28(3):909-913.

Srichairat, N., Taksintum, W. and Chumnapuen, P., 2018. Gross morphological structure of digestive system in water monitor lizard Varanus salvator (Squamata: Varanidae). Walailak Journal of Science and Technology (WJST), 15(3):245-253.

Wetherall, J.D. and Turner, K.J., 1972. Immune response of the lizard, Tiliqua rugosa. Australian Journal of Experimental Biology and Medical Science, 50(1):79-95. 